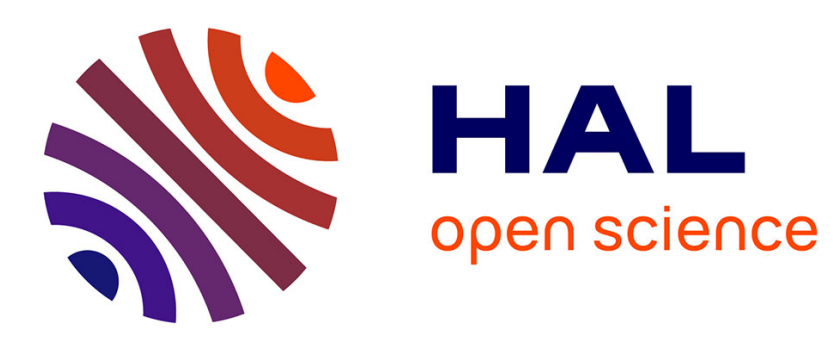

\title{
Design of a clip product based on customer needs for playing acoustic music
}

Julien Veytizou, Hugo Xuereb, Guillaume Thomann

\section{To cite this version:}

Julien Veytizou, Hugo Xuereb, Guillaume Thomann. Design of a clip product based on customer needs for playing acoustic music. 23th CIRP Design Conference 2013, Mar 2013, Bocchum, Germany. pp.00. hal-00787812

\section{HAL Id: hal-00787812 \\ https://hal.science/hal-00787812}

Submitted on 13 Feb 2013

HAL is a multi-disciplinary open access archive for the deposit and dissemination of scientific research documents, whether they are published or not. The documents may come from teaching and research institutions in France or abroad, or from public or private research centers.
L'archive ouverte pluridisciplinaire HAL, est destinée au dépôt et à la diffusion de documents scientifiques de niveau recherche, publiés ou non, émanant des établissements d'enseignement et de recherche français ou étrangers, des laboratoires publics ou privés. 


\title{
Design of a clip product based on customer needs for playing acoustic music
}

\author{
Julien Veytizou ${ }^{1}$, Hugo Xuereb ${ }^{1}$, Guillaume Thomann ${ }^{1}$ \\ ${ }^{1}$ GSCOP - Grenoble Laboratory for Sciences of Design, Optimisation and Production \\ 46, avenue Félix Viallet - 38031 Grenoble Cedex 1 - France \\ Julien.Veytizoulgrenoble-inp.fr
}

\begin{abstract}
Inclusion of uses and users in product design remains a challenge to take up; especially when their characterizations are very specific (it's the case with disabled persons). In the musical domain, a lot of adapted interfaces are manufactured to enable users with disabilities to play music from digital audio. But few of them allow the music practice on acoustic instruments, which is one of the goal identified by the AE2M non-profit association (Ergonomic Adaptation of the Musical Material). In this specific context, this paper presents the design of a universal product which transforms any user environment object to a personalized interface, to play percussion instruments.
\end{abstract}

Keywords: user environment, design, disabled people, acoustic music, robotic musical

\section{Introduction}

Traditionally, designers create products or interfaces for able-bodied users, assumed to have normal motor skills [1]. Atypical users, including people with disabilities, remain outside of these skills and capabilities standards. They must adapt to with existing systems, using technical aids. Unfortunately, these technologies are unusable for people with temporary impairments. They are also not adapted to users whose abilities change over time. The data, detailed in a research report conducted by INSEE (France's National Institute of Statistics and Economic Studies), show a significant need of assistance in handling (only 35.3\% satisfaction for remote handling) [2]. Nevertheless, these means are often abandoned because of their price and complex use. The main reasons for giving up are due to a minimum consideration of future users in design activities.

There are two main groups among system designers for disabled people [3]:

- The first which go to certain well-defined needs and seek a technological solution (social pull). These proponents generally have a good knowledge of disabilities. They are looking primarily practical systems, efficient and robust, sometimes ignoring the more advanced technologies. The risk here might be to focus too much on obsolete technology, unusable or too expensive. 
- The second which go to a technology they have mastered and are looking for applications in the field of disabilities (technology push). The risk here might be to propose solutions for imaginary or non-priority needs.

Integrate multidisciplinary teams in the design process can avoid these risks.

Our research work consists to the development and the manufacture of physical interfaces facilitating access to instrumental music for children with heavy physical disabilities. Currently, disabled user environment are not adapted to their needs and human machine interface. One solution is a custom design of products for each user motor skills. But this process can be lengthy and difficult because of the myriad of user profiles. Moreover, one of the most objectives is to reach low cost production and the large diffusion for disabled customers.

The research question can be written as below: How to design a universal product which would transform any user environment to a personalized interface?

To answer this question, our methodology is the following:

Section 2 presents an identification of needs in our context thanks to a literature review. Three main parts are exposed: future user characteristics, existing adapted system to play music, human machine interaction in musical practice. Thanks to the needs list defined previously, section 3 offers a first prototype based on piezoelectric sensors technology. Its structure is defined with a representation of human machine interaction in our specific context. Its architecture is described in functional component decomposition. After a presentation of test methods, section 4 shows the first results when using this interface for a musical playing.

\section{$2 \quad$ Identification of needs}

As the NF EN ISO 9241-210 UCD Process ${ }^{1}$ recommends, designers take into account the contextual factors as well as the requirements of the future users before producing design solutions.

\subsection{User with disability}

User characteristics define the context in which the product is used. The futures users are children with disability. We are focused on the disability ICF-CY definition (International Classification of Functioning, Disability and Health for Children and Youth), proposed by the WHO (World Health Organization) to understand the terminology of disability [4]. This definition provides a common language that can record the problems occurring during infancy, childhood and adolescence. It is based on body functions and body structures, activity limitations, restrictions participation and environmental factors significant for children and youth (Figure 1).

1. NF EN ISO 9241-210: 'Human-Centred Design Processes for Interactive Systems' Genève, Switzerland, International Organization for Standardization, January, 2011. 


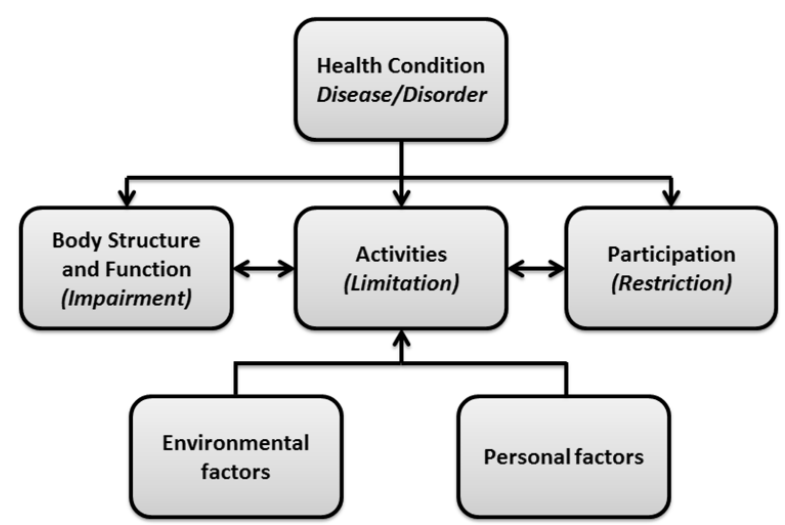

Fig. 1. ICF-CY definition: International Classification of Functioning, Disability and Health for Child and Youth

Disability therefore results from the interaction between a person with health problems and contextual factors (personal and environmental). Impairments refer to modifications of body functions or anatomical structures, such as paralysis. Activity Limitations are difficulties an individual may experience in these activities (walking, eating, playing etc...). Participation restrictions are problems a person may meet to participate in a situation of daily life, such as transportation inaccessibility.

\subsection{Existing adapted system}

This section analyzes existing systems for the practice of music. This analysis can reveal needs, problems and constraints that have not been taken into account.

\subsubsection{To play music with digital audio}

Interfaces designed for disabled people allow musical practice from digital audio:

- The BAO-PAO fits perfectly with the computer-assisted music because it needs to operate a computer and special software. It consists of four rigid steel arches, each terminated by two spheres at the ends. A laser beam passes between the upper sphere and the lower sphere. It generates a sound when the musician crossed it with a drumstick or hand [5].

- TouchTone is an electronic musical instrument. Its goal is to develop musical ability, to develop bimanual coordination and to increase social participation of children with hemiplegic cerebral palsy [6].

- The GUI/RO is a stylus controlled instrument, augmented with resistive force feedback. The system is manufactured through an electromagnetic coil controlled by Arduino board. Sounds and haptic effects are generated by the position on the stylus in touch-sensitive screen [7].

With these solutions, users can play any instrument thanks to synthesize sound. Nerveless, the musical instrument is dematerialized. Indeed, the user doesn't visualize 
a real musical instrument for the music game. Moreover, transportation and equipment installation can be difficult and not adapted with the environment of disabled people.

\subsubsection{To play acoustic music with AE2M project}

Few systems allow the music practice on acoustic instruments. This is the goal of the AE2M non-profit association (Ergonomic Adaptation of the Musical Material) [8]. It provides access to instrumental music for children with disabilities, with the same autonomy level as non-disabled. It's a multidisciplinary team which is surrounded by three main applications specialties (Figure 2): Musicians (by specialized professors in instrumental music and musical manufactory), Paramedical specialists (by doctors, specialist therapists) and Engineers (principally by teachers and engineering students).

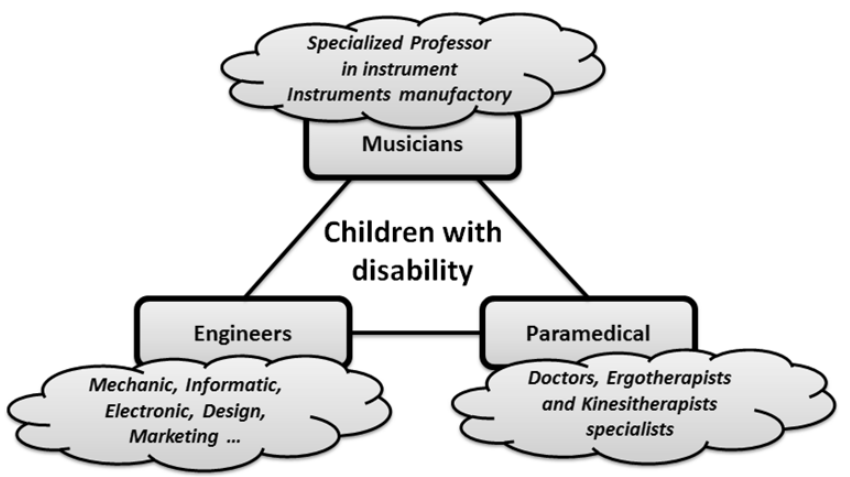

Fig. 2. Competencies triangle of AE2M project

For a better understanding of this competencies triangle, it is necessary to develop the roles and the work of these specialties in the project. Engineers should be familiar with the properties of the musical instrument which children would try to play. So they consult the music specialists of the project. Moreover, engineers have to discuss with the paramedical specialists who spend all their times with disabled children. They know some physical capacities of these children, those needed for the project development.

Generally, interfaces manufactured by the association AE2M allow children to play percussion instruments A specific solution realized is an electromechanical system to allow a strike of the drumstick on percussion instruments (Figure 3). The user activates the system by the means of accessories (push button, pressure effort, etc.) positioned around him according to his ability to perform body motions. With this system, the musician couldn't perform different strike velocity on the instrument and the preparation of musical activities could be long because of the myriad of user profiles. Depending on motor skills (movement, strength ...) and the user environment (wheelchair, tablet ...), this system may have difficulty to be integrated naturally. 


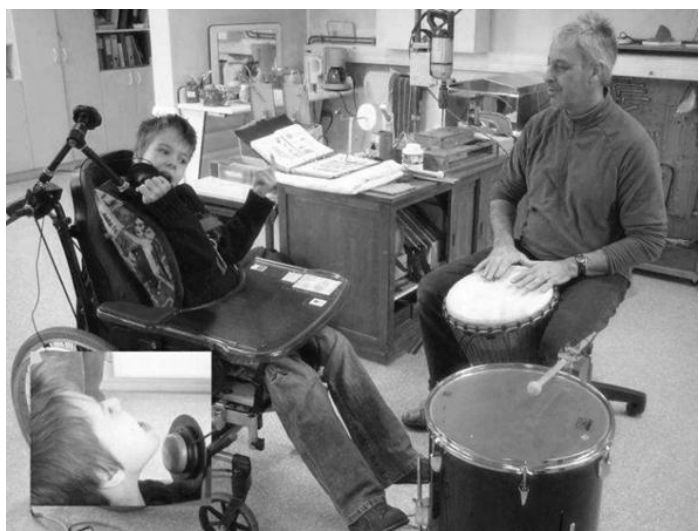

Fig. 3. Use of electromechanical magnet for a playing game

\subsection{Human machine interaction for musical practice}

To define the user tasks, it is important to design the user-system interaction. Metois proposes a generic definition that considers the "musical gesture" as anything that fills the space between the musical intentions (cognition, psychology, and musicology) and musical sounds (waveforms physical) [9]. "Musical gesture" includes the "instrumental gesture" concept. Cadoz defines "Gestural Canal" as a means of acting on the physical world and as a means of two way communication: sending and receiving information. Then, his definition considers the Instrumental Gesture as a communication modality specific at "Gestural Canal" as follow [10]:

- It applies to a material object and there is physical interaction with it,

- In this context of interaction, it will occur physical phenomena,

- These phenomena can then become communicational messages.

\subsection{Synthesis}

These different parts allow describing the needs as well as requirements of our interface realization. In our musical context, we must offer to disabled child with particular health condition, a product which would allow them to enjoy musical play (activities) and even to participate in concert (participation) with the same autonomy level as non-disabled (body structure and function). For musicians and paramedical team, the system must be easy to install and must be integrated naturally to the environment of the user. In addition, the delay between the musical intention of the user and the system response must be transparent. The musician recommends a delay time less than ten milliseconds (between the action of the children and the action of mechanical system). The system must also perform different strike velocity on the instrument. For engineers, the interface must contain a minimum of electronic equipment. If maintenance must be performed, it should be easy. Our proposition is to transform any object in the user environment as an action unit on electromechanical systems. 


\section{Concept solution proposition}

This section offers a concept solution using the previous synthesis. The product structure is defined with a representation of human machine interaction in our specific context. Its architecture is described in functional component decomposition.

\subsection{Product structure}

The product structure is based on our proper representation of human machine interaction using the definition of "musical and instrumental gesture". In our context, the user has a musical intention (Figure 4). He will perform an action on an object environment. This interaction will produce physical phenomena (force, pressure or vibration) that can be controlled by the user (duration, amplitude). These phenomena can thus become communicational messages to the electromechanical system for the strike of the drumstick on the percussion instrument. The essential elements in designing of our future product are:

- A clip sensor for the physical phenomena detection.

- An electronic board to transform these phenomena in action message for actuator positioned on the musical instruments.

The development is inspired from the different work realize by the LEMUR (League of Electronic Musical Urban Robots) which is the producer of the famous Pat Metheny's Orchestrion composed of forty robotic musical instruments. It uses principally stepper motor, hobby servo and solenoids as actuator. They are controlled by a Pulse Width Modulation Signal (PWM) [11][12].

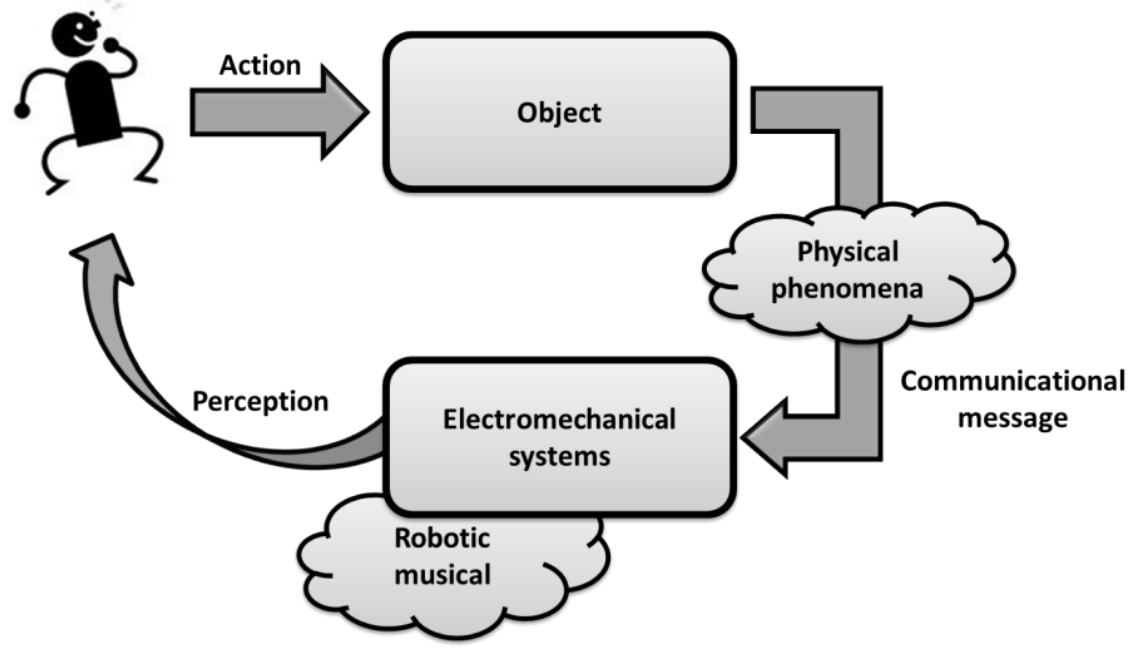

Fig. 4. Human Machine interaction of our interface 


\subsection{Product architecture}

From this previous definition as well as the identification of needs, this part describes the product architecture. It's divided principally in two parts (Figure 5):

- Control part with sensor clip, electronic board and microcontroller input

- Actuator part with microcontroller output, electronic board and mechanical system

The sensor emits a signal. It is interpreted by a microcontroller to control a mechanical system placed on the instrument. These control actions are based on the musical intentions of the user. In our case, the Arduino board corresponds to our expectations. This material is open source, free and easy for everyone to use. After this interpretation, Arduino can generate PWM signals to control a solenoid. But the output current is too weak to command this system. A power signal processing is therefore necessary. All this process must be realized in less than 10 milliseconds.

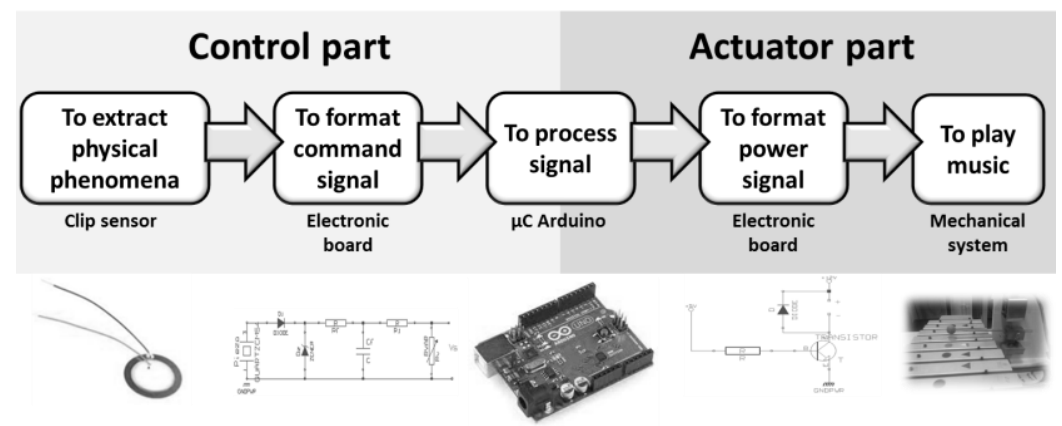

Fig. 8. Architecture of the smart clip sensor

\section{$4 \quad$ Evaluation of the solution}

This section shows an evaluation of the design solution against user needs and requirements. Test methods are presented for the sensor choice and the study of the strike velocity.

\subsection{Tests methods}

The sensor choice will be based on the following main criteria: accuracy, sensitivity, size and of price. Three different sensors performances are studied. They are different in size and form: two circular (Multicomp and Murata) and one rectangular (Prowave). They are arranged in a circular arc at an equal distance (d) from a disturbance area where it will be throw, at the same height, different weights. Sensitivity is measure by an oscilloscope (Figure 6). To study the strike velocity, Musician asks to the user to perform three different strikes (Piano, Mezzo, and Forte) on a plastic box where the clip sensor is located $\left(n^{\circ} 1\right.$ on Figure 7$)$. After signal 
processing ( ${ }^{\circ} 2$ on Figure 7$)$, the drumstick movement $\left(n^{\circ} 3\right.$ on Figure 7$)$ on the instrument $\left(\mathrm{n}^{\circ} 4\right.$ on Figure 7 ) is filmed. Speed strike is analyzed with the Kinovea software, a free and open source solution for video analysis. It is mostly used by sports coaches, animation artists and ergonomics engineers.

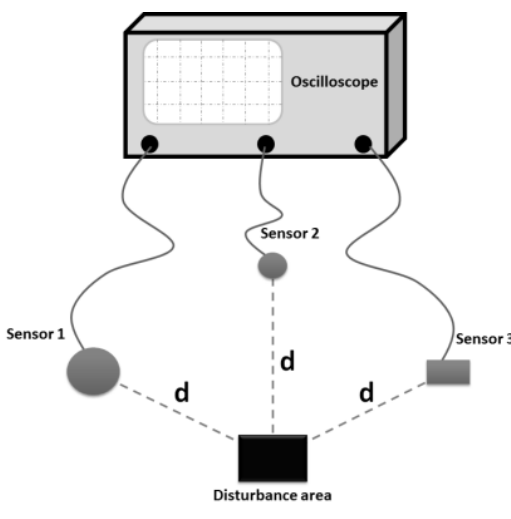

Fig. 6. Test for sensor choice

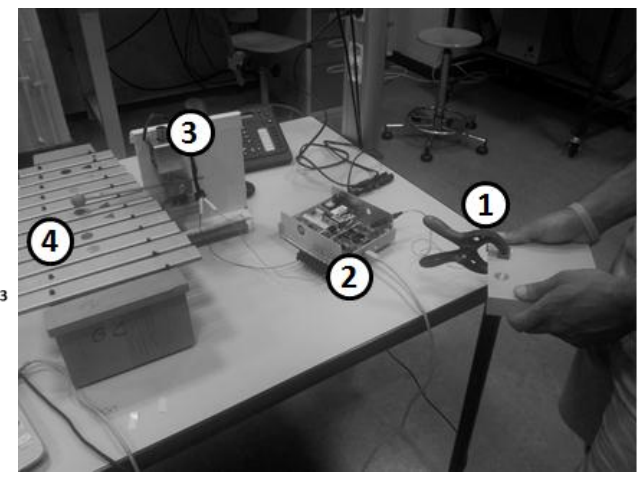

Fig. 7. Test for signal processing and velocity

\subsection{Sensor choice}

Figure 8 shows the sensitivity analyzes of piezoelectric sensors Murata, Multicomp and Prowave. The signal amplitude is measured when the weight is throwing in the disturbance area. For a 500 grams weight, Murata gives a signal of 30.2 volts, Multicomp 9.8 volts and Prowave 2.9 volts. Multicomp exceeds 5 volts for weight greater than 120 grams, Murata for few grams. However, Prowave never exceed this value. For the next experimentation, the strike velocity is analyzed with Murata.

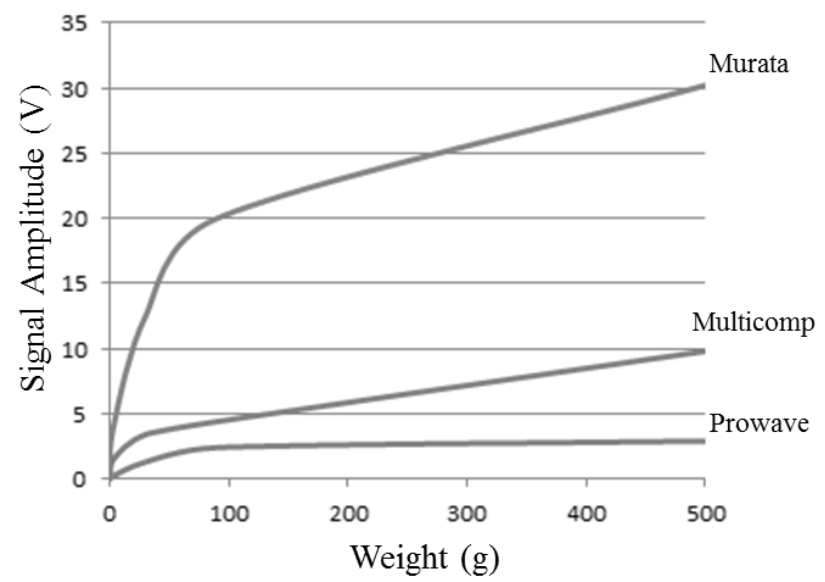

Fig. 8. Sensitivity analyze of piezoelectric sensors 


\subsection{Strike velocity}

Figure 9 shows the strike speed of the drumstick controlled by the mechanical system. Three strike speeds are saved: the first at $0.4 \mathrm{~m} / \mathrm{s}$, the second at $0.7 \mathrm{~m} / \mathrm{s}$ and the third at $1.9 \mathrm{~m} / \mathrm{s}$.

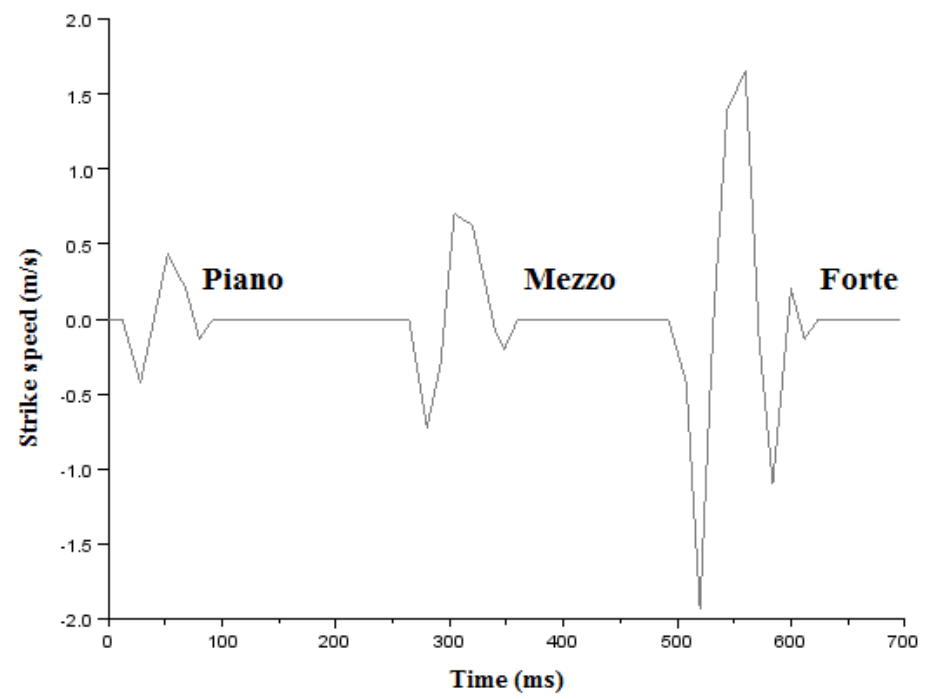

Fig. 9. Strike velocity study with Murata sensor

\section{Discussion}

Our interface allows transforming any user environment object to a percussion musical instrument. Its architecture is simple with low-cost and easy system Arduino, little electronic equipment to facilitate maintenance. Our system is integrated more naturally to the environment of user. For the sensor choice, Murata sensitivity is more efficient. Indeed, a child with low motion disabilities could control musical instrument. The response time of the system is less than two milliseconds (inferior at ten milliseconds recommended by the musician). It's possible to adjust the strike velocity on the instrument with different actions on an object.

\section{Conclusion}

Identification of needs and collaboration with the AE2M multidisciplinary team has allows to generate uses specifications of a product. These specifications have been destined to a team of Research and Development, expert in new technology. Thus, this methodology has led to the design of a universal product which would transform any user environment to a personalized interface. The product structure has defined by a representation of human machine interaction in our context. The product archi- 
tecture is described in functional component decomposition. After these first encouraging results, this system facilities access to instrumental music for users with heavy physical disabilities, but also to increase the uses performance by musicians. The perspectives are focused by the clip design, the increase of the performance of the mechanical system and the "intelligence" of this system (the actuator part is able to adapt to user motor skills).

\section{References}

1. S. Keates, P. J. Clarkson, L.-A. Harrison, et P. Robinson, « Towards a practical inclusive design approach », in Proceedings on the 2000 conference on Universal Usability, New York, NY, USA, 2000, p. 45-52.

2. C. Brouard, «Le handicap en chiffres». CTNERHI Centre Technique National d'Etudes et de Recherches sur les Handicaps et les Inadaptations, 2004.

3. Jean-Claude Sperandio, «Designing technological devices for a normal population, namely also including disabled people and the elderly. », in Pistes, p. Vol 9 No 2, 2007.

4. ICF, «International Classification of Functioning, Disability and Health (ICF) Disability and Health ». 2001

5. BAO- PAO, « http://www.bao-pao.com/index.php ». 2012

6. S. Bhat, «TouchTone: an electronic musical instrument for children with hemiplegic cerebral palsy ", in Proceedings of the fourth international conference on Tangible, embedded, and embodied interaction, New York, NY, USA, 2010, p. 305-306

7. Alexander Müller, Fabian Hemmert, Götz Wintergerst, et Ron Jagodzinski, «Reflective Haptics: Resistive Force Feedback for Musical Performances with Stylus-Controlled Instruments », in Proceedings of the International Conference on New Interfaces for Musical Expression, p. 477-478, 2010

8. AE2M, «AE2M Project - http://projetae2m.free.fr/ ». 2012.

9. E. Métois, «Musical Sound Information - Musical Gestures and Embedding Systems ». $\mathrm{PhD}$ thesis, Massachusetts Institut of Technology, 1996.

10. C. Cadoz, «Gestural channel of the man machine communication: instrumental communication », TSI. Technique et science informatiques, vol. 13, $\mathrm{n}^{\circ} .1$.

11. Ajay Kapur, Eric Singer, Afzal Suleman, et George Tzanetakis, «A comparison of solenoid-based strategies for robotic drumming », ICMC Copenhagen, 2007.

12. Ajay Kapur et Michael Darling, «A Pedagogical Paradigm for Musical Robotics », presented at the New Interfaces for Musical Expression, Sydney, Australia, 2010. 